\title{
In pursuit of surgical success
}

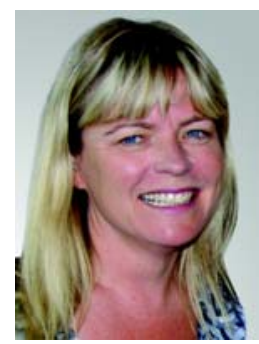

Ruth Armstrong Senior Deputy Editor

mja@mja.com.au

doi: 10.5694/mjal3.c0506

perioperative care (page 407), Waxman describes the ideal

scenario, in which elective patients benefit from

multidisciplinary preoperative assessment and an

"enhanced recovery after surgery" pathway. Preoperative

planning and a "preflight" checklist in the operating theatre pay dividends for patients in their postoperative journey, even in emergency surgery.

With the aim of creating surgeons with a more holistic outlook, Australian standards of practice now include nontechnical competencies including professionalism, communication, leadership and advocacy. Hollands, president of the Royal Australasian College of Surgeons (RACS), describes initiatives to ensure trainee surgeons are versed in these skills and to up-skill practising surgeons (page 400). He makes the important point that such efforts must be clinically relevant for them to have any impact.

The quality of surgical training is obviously relevant to patient safety. But could the training model itself, historically assumed to require full-time dedication, be an obstacle to acquiring the best possible surgeons? And how safe is fulltime training for trainees? These questions arise from a survey of Australasian surgical trainees conducted by McDonald and colleagues (page 423). Only two of the 659 trainees surveyed had secured part-time accredited training positions, although a third of respondents expressed an interest in this model. The authors point out that this deficit in part-time training opportunities may result in applicants with family, personal or professional responsibilities and interests being filtered out of the training pool. Furthermore, the average working hours of full-time Australasian surgical trainees are at a level associated with burnout. In an accompanying commentary (page 426), Williams, censor-inchief of the RACS, confirms at least one part-time accredited surgical training post in Australia has proven successful for both the hospital and the trainee. The RACS has now established a working party to look at extending opportunities for part-time training.

When the medical director of the United Kingdom's National Health Service recently announced plans to publish a league table of mortality and "other" outcomes for British surgeons, the official response of the Royal College of Surgeons and the British Medical Association included a mild warning that uncorrected reporting of mortality rates may lead to an unwillingness of surgeons to take on high-risk cases. Informal commentators were more vocal, raising concerns about patient selection, impact on training, blame of individual surgeons for factors beyond their control, skewed statistics and the logistics of measuring performance (http://www.bjuinternational.com /bjui-blog/individualised-reporting-of-surgical-outcomesin-the-uk). According to Maddern (page 399), public reporting is not yet planned for Australia, but the situation in the UK underscores the challenge for our own developing surgical audit systems of how best to determine, measure and feed back meaningful performance indicators to surgeons and their patients.

Waxman, Hollands and Maddern all present a common observation: it is patients who are driving the need for information, quality and assurances of safety. Undergoing surgery is certainly safer now than when Chiene made his ironic observation. But it remains true that, particularly from the patient's perspective, there is no such thing as a successful operation with a poor outcome.

Writing with Light - Thanks to everyone who entered our Writing with Light photography competition. This issue's winning entry is published on page 452. It is an ongoing competition, so we look forward to viewing and publishing many more of your photographs in future.

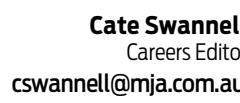

Careers follows $p 452$

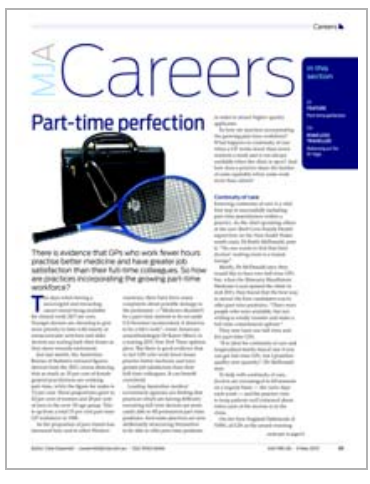

Many general practitioners opt to work fewer than full-time hours in a bid to achieve work-life balance. There is evidence to suggest that they end up being better doctors, and with more job satisfaction, than their full-time colleagues. How does a successful practice juggle continuity of care, the needs of its part-time doctors and the needs of its patients? Annabel

McGilvray digs into the issue (pages C1, C2). Speaking of part-time doctoring, Dr Arjun von Caemmerer combines his general practice with running his yoga school, creative writing, poetry and a passion for music. Cate Swannell spoke with him about his quest for balance and excellent patient care (page C4). 